\section{OPEN ACCESS}

Edited by:

Halina Was,

Military Institute of Medicine, Poland

Reviewed by:

Prashant Kaushik,

University of Valencia, Spain

Omid Gholami,

Sabzevar University of Medical

Sciences, Iran

*Correspondence:

Samira Eghbali

eghbalis98@gmail.com

Specialty section:

This article was submitted to Pharmacology of Anti-Cancer Drugs,

a section of the journal

Frontiers in Pharmacology

Received: 21 April 2021

Accepted: 09 June 2021

Published: 22 June 2021

Citation:

Tayarani-Najaran Z,

Tayarani-Najaran N and Eghbali S (2021) A Review of Auraptene as an

Anticancer Agent.

Front. Pharmacol. 12:698352.

doi: 10.3389/fphar.2021.698352

\title{
A Review of Auraptene as an Anticancer Agent
}

\begin{abstract}
Zahra Tayarani-Najaran ${ }^{1,2}$, Nilufar Tayarani-Najaran ${ }^{3}$ and Samira Eghbali ${ }^{4,5 *}$
${ }^{1}$ Medical Toxicology Research Center, Mashhad University of Medical Sciences, Mashhad, Iran, ${ }^{2}$ Targeted Drug Delivery Research Center, Pharmaceutical Technology Institute, Mashhad University of Medical Sciences, Mashhad, Iran, ${ }^{3}$ Department of Prosthodontics, School of Dentistry, Mashhad University of Medical Sciences, Mashhad, Iran, ${ }^{4}$ Department of Pharmacognosy, School of Pharmacy, Birjand University of Medical Sciences, Birjand, Iran, ${ }^{5}$ Cellular and Molecular Research Center, Birjand University of Medical Sciences, Birjand, Iran
\end{abstract}

Auraptene is a bioactive monoterpene coumarin isolated from Citrus aurantium and Aegle marmelos that belong to the Rutaceae family. Auraptene can modulate intracellular signaling pathways that control cell growth, inflammation and apoptosis and can exert pharmacological properties such as anti-bacterial, anti-fungal, antileishmania and antioxidant activity. Auraptene had inhibitory and chemo-preventive effects on the proliferation, tumorigenesis and growth of several cancer cell lines through increase in the activity of glutathione S-transferase, formation of DNA adducts and reduction of the number of aberrant crypt foci. Auraptene exhibits anticancer effects via targeting different cell signaling pathways such as cytokines, genes modulating cellular proliferation, growth factors, transcription factors and apoptosis. The present review is a detailed survey of scientific researches on the cytotoxicity and anticancer activity of Auraptene on cancer cells and tumor bearing animals.

Keywords: Auraptene, Rutaceae, cytotoxicity, anticancer activity, cancer cells

\section{INTRODUCTION}

Coumarins are a large class of natural compounds mainly found in the Apiaceae, Rutaceae, and Composita families. The three main groups of coumarins are: 1) ring-fused coumarins, 2) substituted coumarins and 3) C- and O-prenylcoumarins (Eghbaliferiz et al., 2020).

Auraptene, 7-geranyloxycoumarin, is a member of umbelliferone coumarins in which the phenolic hydrogen has been replaced by a geranyl group. Auraptene is isolated from many of the edible fruits and vegetables of the genus Ferula and Citrus like lemons, grapefruits and oranges. Auraptene indicates a variety of therapeutic properties such as antidiabetic, antiprotozoal, antibacterial, anti-fungal, anti-genotoxic, antileishmanial, anti-inflammatory, antihelicobacter, and immunomodulatory activities (Bibak et al., 2019). This compound showed significant effect on the treatment of several chronic illnesses including hypertension, nonalcoholic fatty liver and cystic fibrosis (Derosa et al., 2016; Figure 1).

Tumor is a group of cells/tissues due to the activation of various oncogenes or inactivation of tumor suppressors has lost its control on the normal growth at the gene level. Tumor tissue can be divided into malignant (cancerous) and benign (non-cancerous) according to the size and growth features. Malignant tumor grows rapidly and often infiltrate to the surrounding tissues without envelops on the surface. Patients with advanced cancer after surgical excision exhibited severe systemic symptoms and high recurrence rate, that causing a big challenge for cancer therapy. In view of the enormous damage caused by cancer, the development of new antitumor treatments has become a research hotspot. Natural products are a good source of 
<smiles>CC(C)=CCC/C(C)=C/COc1ccc2ccc(=O)oc2c1</smiles>

FIGURE 1 | Structure of auraptene.

antitumor compounds. In recent years, auraptene have drawn scientists' attention because of its broad-spectrum and effective antitumor activities (Fu et al., 2020).

The information and literature available in this review have been obtained through the Pubmed, Scopus, and Science Direct databases for English articles published until 2020. For this purpose, we used appropriate keywords including "auraptene" or "coumarin" and "cancer" or "cytotoxic." The purpose of this review is to summarize the therapeutic effect and mechanism of auraptene in different types of cancers.

\section{ANTICANCER PROPERTIES OF AURAPTENE}

The cytotoxic, antitumor and anticancer activities of auraptene have been addressed in many in vivo and in vitro studies. The underling mechanisms have been discussed in the next paragraphs and summarized in Figure 2 and Table 1 and Figure 3 displays the molecular mechanism of auraptene in cancer treatment.

\section{Breast Cancer}

Breast cancer is the most widespread and second leading cause of death in the female adult population. Hormone positive and negative Breast cancer may be treated according to the hormone status of the cancer cells. Hormone suppressive treatment is assigned to hormone sensitive cells (EghbaliFeriz et al., 2018).

Auraptene, a prenyloxycoumarin from Citrus species, demonstrated anticancer activity against breast cancer. The underlying mechanism responsible for this effect is the modulation of estrogen receptors (ERs) and suppression of cholesterol acyl transferase (ACAT) (De Medina et al., 2010). Auraptene inhibited the proliferation of MDA-MB-231 and MCF-7 human breast cancer cells and significantly inhibited cyclin D1 dose-dependently and delayed tumor progression in rat mammary tumors (Krishnan et al., 2009). It has also been reported that the dietary administration of auraptene delayed tumor expansion (or extension). Auraptene reduced cyclin D1 protein expression and inhibition of insulin-like growth factor1(IGF-1) in MCF-7 cells (Krishnan and Kleiner-Hancock, 2012). In another study, auraptene from Ferula szowitsiana root indicated anti-tumor activity in human breast cancer cells via up-regulation of caspase- 3 and caspase- 8 and down-regulation of MMP-9, MMP-2, VEGFR-1 (vascular endothelial growth factor), and VEGFR-2 genes (Charmforoshan et al., 2019). Motlagh et al. investigated the cytotoxic effects of umbelliprenin and auraptene against MCF-7 cell lines. Auraptene was more cytotoxic than umbelliprenin and exerted this effect through down-regulation of Myeloid Cell Leukaemia Type-1 (Mcl-1) mRNA expression (Motlagh and Gholami, 2017).

\section{Colorectal Cancer}

Colorectal cancer is one of the most prevalent and third leading cause of death among patients in the world. The best strategy for treatment of colorectal cancer is surgical resection combined with chemotherapy and radiation (Kaur and Kaur, 2015).

Auraptene at a concentration of $10 \mu \mathrm{M}$ significantly inhibited the growth and formation of HT-29 and HT-116 cells in vitro. Auraptene was reported to suppress the expression of CD166 and

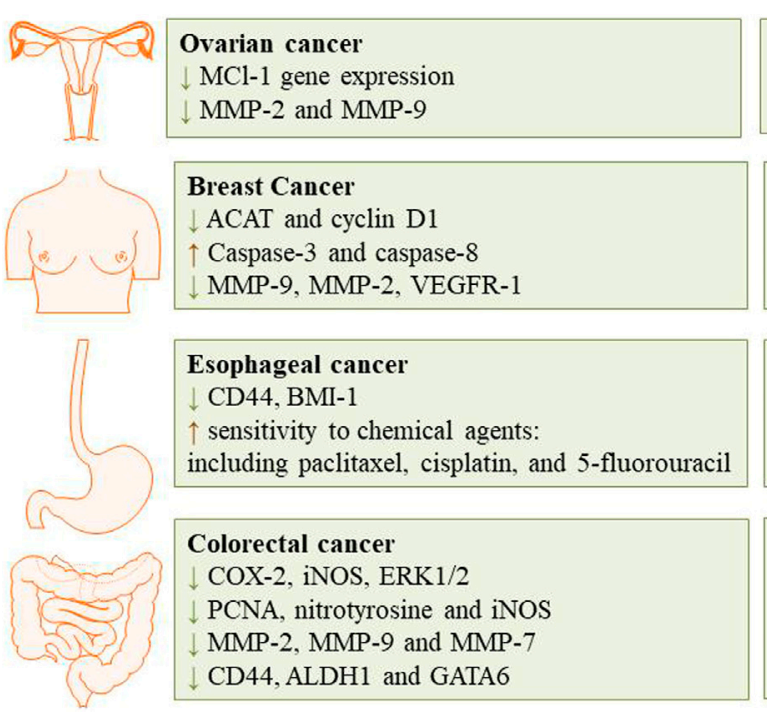

Skin cancer

TPA and $\mathrm{O}_{2}^{-}$

LPS-induced NF- $\kappa \mathrm{B}$ activation

\section{Gastric cancer}

ERK $1 / 2$ and IL- 8 production

$\mathrm{mTOR}$ and $\mathrm{CD} 74$ production

P53 and Akt

\section{Hepatic cancer \\ GST and TGF- $\alpha$ \\ HSCs activation \\ mitochondrial respiration and $\mathrm{HIF}-1 \alpha$ signaling}

\section{Prostate cancer}

$\uparrow$ Caspase- $9 / 3$ and Bax

$\mathrm{Bcl}-2$ and $\mathrm{MCl}-1$

$\uparrow$ TUNEL-positive cells and sub-G1 population $\uparrow$ PARP Cleavage
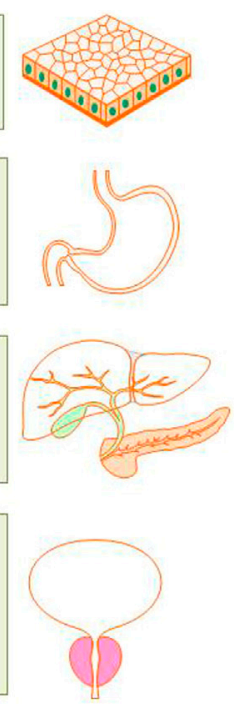

FIGURE 2 | The inhibition effects of auraptene in different type of cancer. 
TABLE 1 | The antitumor experiment of auraptene in vitro and in vivo.

\begin{tabular}{|c|c|c|c|c|c|}
\hline $\begin{array}{l}\text { Type of } \\
\text { cancer }\end{array}$ & $\begin{array}{l}\text { Experimental } \\
\text { model }\end{array}$ & Dose & $\mathrm{IC}_{50}$ & Mechanism & References \\
\hline Breast cancer & $\begin{array}{l}\text { SW-620, MDA-MB- } \\
\text { 231, MCF-7 }\end{array}$ & $0.1-100 \mu \mathrm{M}$ & $4.18 \mu \mathrm{g} / \mathrm{ml}$ & Modulation of ERs and suppression of acyl-CoA & De Medina et al. (2010) \\
\hline Breast cancer & $\begin{array}{l}\text { MDA-MB-231, MCF- } \\
7 \text { and rat }\end{array}$ & $\begin{array}{l}1-50 \mu \mathrm{M} 200 \\
500 \mathrm{ppm}\end{array}$ & $85 \%$ inhibition & Inhibition of cyclin D1 & Krishnan et al. (2009) \\
\hline Breast cancer & $\mathrm{MCF}-7$ & $250 \mu \mathrm{g} / \mathrm{ml}$ & $61.3 \mu \mathrm{g} / \mathrm{ml}$ & $\begin{array}{l}\text { Up-regulation of caspase- } 3 \text { and caspase- } 8 \text { and } \\
\text { down-regulation of MMP9, MMP2, VEGFR-1, and } \\
\text { VEGFR-2 }\end{array}$ & $\begin{array}{l}\text { Charmforoshan et al. } \\
\text { (2019) }\end{array}$ \\
\hline Breast cancer & MCF-7 & $10,20,40 \mu \mathrm{g} / \mathrm{ml}$ & $\begin{array}{c}17.26-29.66 \\
\mu \mathrm{g} / \mathrm{ml}\end{array}$ & Down-regulation of $\mathrm{Mcl}-1 \mathrm{mRNA}$ & $\begin{array}{l}\text { Motlagh and Gholami } \\
(2017)\end{array}$ \\
\hline Breast cancer & MCF-7 cells & 500 ppm & & $\begin{array}{l}\text { Reduction of cyclin D1 protein expression and } \\
\text { inhibition of IGF-1 }\end{array}$ & $\begin{array}{l}\text { Krishnan and } \\
\text { Kleiner-Hancock (2012) }\end{array}$ \\
\hline Gastric cancer & MGC-803 cells & $0-4 \mu \mathrm{M}$ & $0.78-10.78 \mu \mathrm{M}$ & Expression of apoptosis- related protein & Li et al. (2018) \\
\hline Gastric cancer & C57BL/6 mice & 100,500 ppm & & Inhibition of CD74 production & Sekiguchi et al. (2012) \\
\hline Gastric cancer & $\mathrm{NCl}-\mathrm{N} 87$ cells & $20 \mu \mathrm{M}$ & & Reduction of ERK $1 / 2$ activation and IL-8 production & Sekiguchi et al. (2010) \\
\hline Gastric cancer & SNU-1 cells & $25-200 \mu \mathrm{g} / \mathrm{ml}$ & $\leq 25 \mu \mathrm{M}$ & $\begin{array}{l}\text { Inhibition of mTOR, activation of p53 and increase in } \\
\text { the phosphorylation of Akt }\end{array}$ & Moon et al. (2015) \\
\hline Colon cancer & $\begin{array}{l}\text { HT-29 and HT-116 } \\
\text { cells }\end{array}$ & $10 \mu \mathrm{M}$ & $\geq 50 \%$ & $\begin{array}{l}\text { Suppression of CD166 and CD44 and inhibition of } \\
\text { colonospheres }\end{array}$ & Epifano et al. (2013) \\
\hline Colon cancer & F344 rats & 100,500 ppm & & Activation of the phase II enzymes QR and GST & $\begin{array}{l}\text { Tanaka et al. (1998a); } \\
\text { Tanaka et al. (1997) }\end{array}$ \\
\hline Colon cancer & $\begin{array}{l}\text { C57BL/KsJ-db/db } \\
\text { mice }\end{array}$ & $10 \mathrm{mg} / \mathrm{kg}$ & & $\begin{array}{l}\text { Inhibition of COX-2 and iNOS, reduction of cell } \\
\text { proliferation and lipid profiles }\end{array}$ & Hayashi et al. (2007) \\
\hline Colon cancer & $\begin{array}{l}\text { C57BL/KsJ-db/db } \\
\text { mice }\end{array}$ & $10 \mathrm{mg} / \mathrm{kg}$ & $67-80 \%$ inhibition & $\begin{array}{l}\text { Reduction of triglycerides and anti-inflammatory } \\
\text { activity of auraptene }\end{array}$ & Tanaka et al. (2008) \\
\hline Colon cancer & CD-1 (ICR) mice & 100,500 ppm & $63-83 \%$ inhibition & $\begin{array}{l}\text { Suppression of colonic inflammation and modulation } \\
\text { of proinflammatory cytokines }\end{array}$ & Tanaka et al. (2010) \\
\hline Colon cancer & HT-29 cell line & $1-50 \mu \mathrm{M}$ & 2.8 and $3 \mu \mathrm{M}$ & Suppression of proMMP-7 and inhibition of ERK1/2 & Kawabata et al. (2006b) \\
\hline Colon cancer & ICR mice & 100,500 ppm & & Reduction of COX-2, PCNA, iNOS & Kohno et al. (2006) \\
\hline Colon cancer & $\begin{array}{l}\text { Colonic mucosa } \\
\text { mouse }\end{array}$ & $0.1 \% \mathrm{w} / \mathrm{w}$ & $82 \%$ inhibition & Inhibition of MMP-2, MMp-9 and suppression DSS & Kawabata et al. (2006a) \\
\hline Colon cancer & HT29 cells & $10,20 \mu \mathrm{g} / \mathrm{ml}$ & $39 \mu \mathrm{g} / \mathrm{ml}$ & $\begin{array}{l}\text { Reduction of hyperthermia and down-regulation of } \\
\text { HSP27 }\end{array}$ & Moussavi et al. (2018) \\
\hline Colon cancer & HT29 cells & $\begin{array}{l}10,20,40, \text { and } \\
80 \mu \mathrm{g} / \mathrm{ml}\end{array}$ & $31.8-42.1 \%$ & $\begin{array}{l}\text { Down regulation of CD44, ALDH1 and inhibited } \\
\text { expression of GATA6 }\end{array}$ & Moussavi et al. (2017) \\
\hline Hepatic cancer & F344 rats & 100,500 ppm & $83 \%$ inhibition & Reduction of GST, TGF- $\alpha$ & Sakata et al. (2004) \\
\hline Hepatic cancer & F344 rats & 100,500 ppm & & $\beta$-catenin mutation & Hara et al. (2005) \\
\hline Hepatic cancer & C57BL/6 mice & $30 \mathrm{mg} / \mathrm{kg}$ & & $\begin{array}{l}\text { Reduction of toxic bile acids, inhibition of inflammation } \\
\text { and HSCs activation }\end{array}$ & Gao et al. (2018) \\
\hline Hepatic cancer & Rat & 500 ppm & & Nob induction of cell cycle inhibition and apoptosis & Ohnishi et al. (2004) \\
\hline Hepatic cancer & RCC4 cell line & $0-100 \mu \mathrm{M}$ & & $\begin{array}{l}\text { Inhibition the mitochondrial respiration and blockade } \\
\text { HIF-1a }\end{array}$ & Jang et al. (2015) \\
\hline Prostate cancer & PC3 and DU145 & $30,60 \mu \mathrm{M}$ & $30-45 \%$ & $\begin{array}{l}\text { Activation of caspase- } 9 / 3 \text {, Bax, inhibition of Bcl-2 and } \\
\text { Mcl-1, increase the TUNEL-positive cells }\end{array}$ & Lee et al. (2017) \\
\hline Prostate cancer & PC3 and DU145 & 500 ppm & & Induction of apoptosis and cell cycle arrest & Tang et al. (2007) \\
\hline Skin cancer & ICR mouse skin & $18 \mu \mathrm{M}$ & $450 \mu \mathrm{M}$ & Inhibition of TPA and suppression of $\mathrm{O}_{2}^{-}$ & Murakami et al. (1997) \\
\hline Skin cancer & C57BL/6 mice & $500,1,000 \mathrm{mg} / \mathrm{kg}$ & & $\begin{array}{l}\text { Induction of apoptosis, inhibition of metastasis of } \\
\text { B16BL6 melanoma cells }\end{array}$ & Tanaka et al. (2000) \\
\hline Skin cancer & Xenograft mouse & $200 \mathrm{mg} / \mathrm{kg}$ & $84 \%$ inhibition & Suppression of LPS-induced NF-kB activation & $\begin{array}{l}\text { Kleiner-Hancock et al. } \\
\text { (2010) }\end{array}$ \\
\hline Skin cancer & M4Beu melanoma & $10 \mu \mathrm{g} / \mathrm{ml}$ & $17.1 \mu \mathrm{M}$ & $\begin{array}{l}\text { Induction of caspase-dependent apoptosis and cell- } \\
\text { cycle arrest }\end{array}$ & Barthomeuf et al. (2008) \\
\hline Ovarian cancer & Hela cell line & $10,20,40 \mu \mathrm{g} / \mathrm{ml}$ & $\begin{array}{c}13.33-13.87 \mu \mathrm{g} / \\
\mathrm{ml}\end{array}$ & Down-regulation of $\mathrm{MCl}-1$ gene expression & $\begin{array}{l}\text { Motlagh and Gholami } \\
(2017)\end{array}$ \\
\hline Ovarian cancer & $\begin{array}{l}\text { Hela and A2780 cell } \\
\text { line }\end{array}$ & $12.5-100 \mu \mathrm{M}$ & $\begin{array}{l}31.49 \text { and } \\
47.93 \mu \mathrm{M}\end{array}$ & Reduction of MMP-2 and MMP-9 enzymatic activity & Jamialahmadi et al. (2018) \\
\hline $\begin{array}{l}\text { Esophageal } \\
\text { cancer }\end{array}$ & KYSE30 cells & $20 \mu \mathrm{g} / \mathrm{ml}$ & $76-80 \mu \mathrm{g} / \mathrm{ml}$ & Reduction expression of CD44, BMI-1 & Saboor-Maleki et al. (2017) \\
\hline $\begin{array}{l}\text { Esophageal } \\
\text { cancer }\end{array}$ & KYSE30 cells & $10,20,40 \mu \mathrm{g} / \mathrm{ml}$ & $\begin{array}{l}11.75-15.25 \mu \mathrm{g} / \\
\mathrm{ml}\end{array}$ & Down-regulation of $\mathrm{Mcl}-1$ gene expression & $\begin{array}{l}\text { Motlagh and Gholami } \\
(2017)\end{array}$ \\
\hline Leukaemia & Jurkat cells & $20 \mu \mathrm{g} / \mathrm{ml}$ & $16.5 \mu \mathrm{g} / \mathrm{ml}$ & $\begin{array}{l}\text { Activation of caspase cascade, caspase- } 8 \text { and } \\
\text { caspase- } 3 \text {, degradation of PARP and suppression of } \\
\text { Bcl-xL }\end{array}$ & Jun et al. (2007) \\
\hline Leukaemia & Jurkat cells & $10,20,40 \mu \mathrm{g} / \mathrm{ml}$ & $11.3-11.49 \mu \mathrm{g} / \mathrm{ml}$ & Down-regulated Mcl-1 mRNA expression & \\
\hline
\end{tabular}


TABLE 1 | (Continued) The antitumor experiment of auraptene in vitro and in vivo.

\begin{tabular}{|c|c|c|c|c|c|}
\hline $\begin{array}{l}\text { Type of } \\
\text { cancer }\end{array}$ & $\begin{array}{l}\text { Experimental } \\
\text { model }\end{array}$ & Dose & $I_{50}$ & Mechanism & References \\
\hline & & & & & $\begin{array}{l}\text { Motlagh and Gholami } \\
(2017)\end{array}$ \\
\hline $\begin{array}{l}\text { Oral } \\
\text { carcinogenesis }\end{array}$ & F344 rats & 100,500 ppm & $63-91 \%$ reduction & $\begin{array}{l}\text { Suppression of 4-NQO activity, decreased dysplastic } \\
\text { lesions, inhibited the expression of cell proliferation }\end{array}$ & Tanaka et al. (1998b) \\
\hline
\end{tabular}

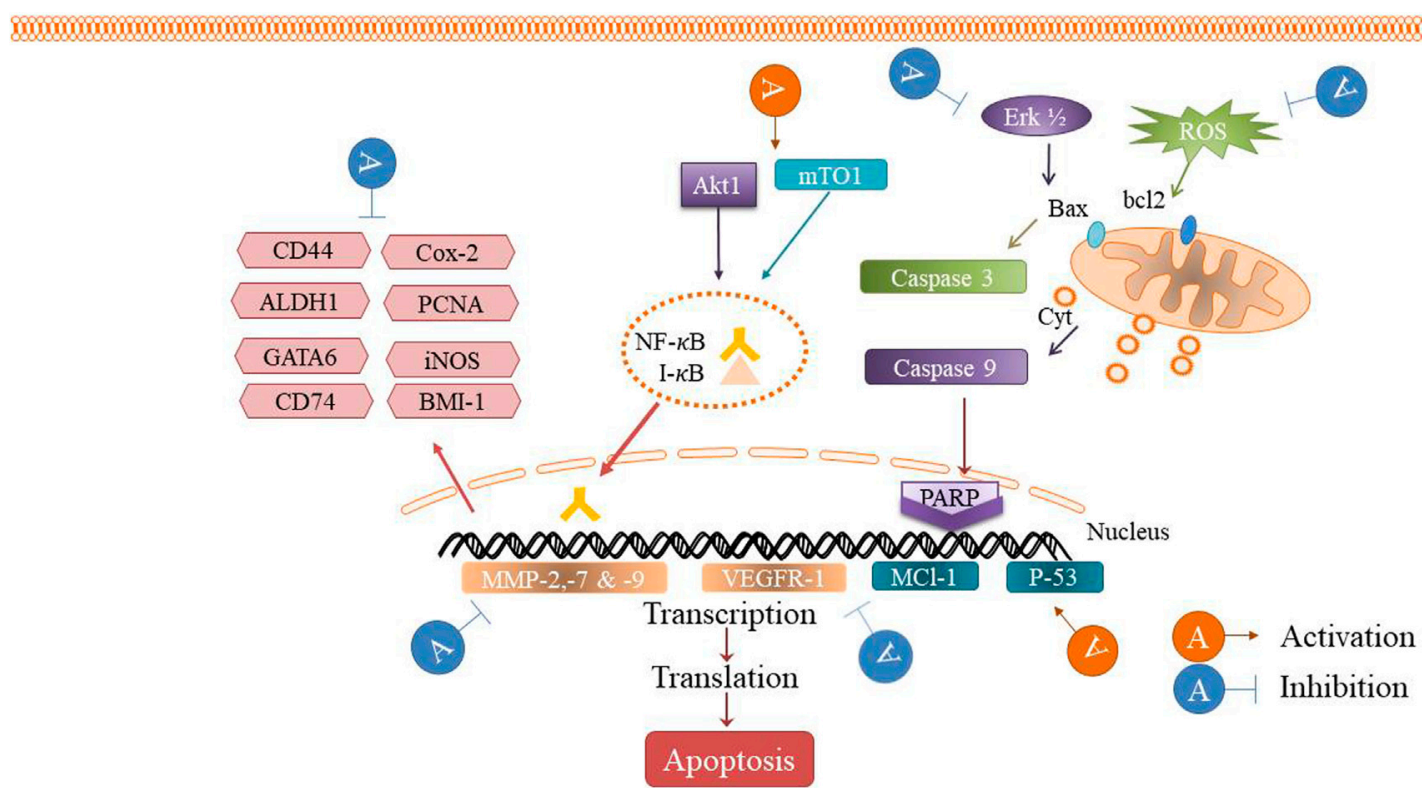

FIGURE 3 | The antitumor mechanism of auraptene.

CD44 in chemo-resistant HT-29 cells and inhibit the formation of colonospheres and growth of both chemo-resistant and wildtype colon cancer cells (Epifano et al., 2013). The administration of auraptene significantly inhibited the development of azoxymethane (AOM)-induced colonic aberrant crypt foci (ACF) in male F344 rats. The mechanisms responsible for this effect were activation of the phase II enzymes QR (quinone reductase) and GST (glutathione Stransferase), reduction of lipid peroxidation and suppression of cell proliferation biomarkers such as ornithine decarboxylase activity, 5-bromo29-deoxyuridine labeling-index and polyamine content in the colonic mucosa (Tanaka et al., 1997; Tanaka et al., 1998a). In another study, administration of auraptene $(10 \mathrm{mg} / \mathrm{kg})$ significantly inhibited the incidence of colon carcinogenesis in C57BL/KsJ-db/db mice. The inhibition of COX-2 and iNOS in colonic epithelial cells, reduction of cell proliferation, lipid profiles and induction of apoptosis was responsible for this effect (Hayashi et al., 2007). Also, the incidence and multiplicity of colonic adenocarcinomas is suppressed by administration of collinin and auraptene at dose of 0.05 and $0.01 \%$, respectively in clitis- and obesity-related colon tumorigenesis models in $\mathrm{C} 57 \mathrm{BL} / \mathrm{KsJ}-\mathrm{db} / \mathrm{db}$ mice. This activity attributed to anti-inflammatory activity of auraptene and collinin
(Tanaka et al., 2008). Auraptene has been reported to prevent the proliferation of colorectal cancer by modulation of inflammatory and expression of proinflammatory cytokines in CD-1 (ICR) mice. These results indicate that the administration of auraptene suppresses the colonic inflammation and modulates proinflammatory cytokines including interleukin (IL)-6 and IL-1b, tumor necrosis factor-a, nuclear factor-kappaB, Stat3 and NF-E2-related factor 2 in adenocarcinomas (Tanaka et al., 2010). In a study conducted by Kawabata et al., auraptene suppressed the growth of human colorectal adenocarcinoma HT-29 cell line. The suppression of proMMP-7 (Matrix metalloproteinase) production and inhibition of extracellular signal-regulated kinase (ERK1/2) protein translation responsible for this effect (Kawabata et al., 2006b).

Kohno et al. reported that auraptene significantly reduced the rates of cyclooxygenase (COX)-2, proliferating cell nuclear antigen (PCNA), nitrotyrosine and inducible nitric oxide (iNOS) in adenocarcinomas. Also, auraptene increased the apoptotis and suppressed the occurrence of colonic adenocarcinoma in male ICR mice (Kohno et al., 2006). It addition, auraptene inhibited MMP-2, MMP-9 expression in HT-29 human colon cancer cells suggesting the anti-metastatic activity of auraptene (Kawabata et al., 2006a). In another study, 
auraptene reduced the toxicity of hyperthermia in human colon adenocarcinoma HT29 cells as a new and important therapeutic strategy usually used as an adjunct to cancer treatment, which was verified by down-regulation of HSP27 (Moussavi et al., 2018). Jalilzadeh et al. reported that nano-encapsulated formulations with biodegradable penta-block PLA-PCL-PEG-PCL-PLA and triblock PCL-PEG-PCL increase the bio-distribution, solubility and delivery of aurapetne to targeted sites and improve the anticancer activity of auraptene especially in colon cancer cells (Jalilzadeh et al., 2020). In colon adenocarcinoma cells, synergism between auraptene and ionizing radiation increased the efficacy of treatment on HT29 cells. Auraptene down regulated CD44, ALDH1 (aldehyde dehydrogenase 1) and inhibited the expression of GATA6 (GATA binding protein 6) (Moussavi et al., 2017). Coadministration of auraptene and radiotherapy for treatment of colon carcinoma cells was investigated in vitro and in vivo. Increase in radiotherapy effects by AUR was observed and confirmed by increased number of apoptotic cells. In vivo, after administration of AUR + radiotherapy significant regression in tumor size, down regulation of Cyclin D1 and CD44, involvement of PI3K-AKT-mTORC signaling pathway and Caspase-3 was observed (Salari et al., 2020).

\section{Gastric Cancer}

The one of the most common malignancies and third leading cause of death worldwide is gastric cancer. The main therapeutic approach for the treatment of gastric cancer is chemotherapy (Torre et al., 2015).

The major human pathogen that plays an important role in gastric cancer and chronic gastritis is Helicobacter pylori. Auraptene inhibited Helicobacter pylori and CD74 production by reduction of extracellular signaling-regulated kinase (ERK) $1 / 2$ activation and IL-8 production in NCI-N87 gasteric carcinoma cells (Sekiguchi et al., 2010). It has also been reported that auraptene suppresses Helicobacter pylori adhesion. The mechanism attributed to this activity was inhibition of CD74 production and reduction of inflammatory cytokine expression such as tumor necrosis factor- $\alpha$ and interleukin- $1 \beta$ in $\mathrm{C} 57 \mathrm{BL} / 6$ mice (Sekiguchi et al., 2012). In another study auraptene, indicated anticancer effect against SNU-1 gastric cancer cells. The underlying mechanism was induction of apoptosis and cell cycle arrest by inhibition of mTOR signaling pathway and activation of p53 along with increase in the phosphorylation of Akt (Moon et al., 2015). Li et al. reported that four new terpene coumarins with notable changes in the skeletal backbone from $2-Z$ auraptene, a synthesized monoterpene coumarin, demonstrate antiproliferative activity against human gastric cancer cells (MGC-803) with $\mathrm{IC}_{50}$ values of $0.78 \pm 0.13-10.78 \pm 1.83 \mu \mathrm{M}$ and induce apoptosis (Li et al., 2018).

\section{Hepatic Cancer}

As one of the most common types of liver cancer, Hepatocellular carcinoma (HCC) is seen most often in people suffering from chronic liver diseases such as hepatitis B or hepatitis C virus infected individuals. Plant based natural products are routinely used as adjuvants to chemotherapeutics (Yang et al., 2019).

Auraptene was introduced as a powerful chemopreventive agent against $\mathrm{N}, \mathrm{N}$-diethylnitrosamine (DEN) that initiated hepatocarcinogenesis in male F344 rats. In one study, the consumption of AUR at doses of 100 and 500 ppm during DEN exposure reduced the numbers of glutathione S-transferase (GST) and transforming growth factor (TGF)- $\alpha$ and also suppressed the incidence of liver cell carcinoma (Sakata et al., 2004). It has also been reported that daily consumption of auraptene during DEN exposure inhibited hepatocellular carcinoma via $\beta$-catenin mutation in male F344 rats (Hara et al., 2005). Gao et al. investigated the hepatoprotection of auraptene against thioacetamide (TAA)induced hepatic fibrosis in mice. The underlying mechanism was reduction of toxic bile acids, inhibition of inflammation, and activation of hepatic stellate cells (HSCs), all of which were related to the activation of farnesoid X receptor (FXR) (Gao et al., 2018). It seems inhibition of HCC cell growth and cell cycle arrest are not the mechanisms of action of auraptene in hepatocellular carcinoma of rat when compared with nobiletin (Ohnishi et al., 2004). In another study which investigated F344 rats, similar data was obtained and auraptene did not inhibit cell proliferation (Kitano et al., 2000).

Hypoxia-inducible factor $1 \alpha$ (HIF-1 $\alpha$ ) is an important regulator of cancer metabolism, angiogenesis and migration which is produced in renal cell carcinoma (RCC). Jang et al., reported auraptene suppresses the progression of RCC through inhibition of mitochondrial respiration and blockade of HIF-1a signaling, without any cytotoxic effects (Jang et al., 2015).

\section{Prostate Cancer}

As the main leading cause of death among men, prostate cancer is routinely treated with chemotherapy, hormonal therapy and radiotherapy. Some natural products have shown promising effects as adjuvant treatments for prostate cancer (Lee et al., 2017).

Lee et al. investigated the anticancer mechanism of auraptene in PC3 and DU145 prostate cancer cells. Auraptene induces apoptosis in prostate cancer cells through activation of caspase-9/3 and Bax, inhibition of Bcl-2 and myeloid cell leukemia 1 (Mcl-1), increases in the number of transferase dUTP nick end labeling (TUNEL)-positive cells and sub-G1 population, and regulation of apoptosis-related proteins such as poly (ADP-ribose) polymerase (PARP) (Lee et al., 2017). In another study, the growth of androgen positive DU145 and PC3 human prostate cancer cells was inhibited by both nobiletin and auraptene in a dose-dependent manner via induction of apoptosis and cell cycle arrest (Tang et al., 2007).

\section{Skin Cancer}

Melanoma and nonmelanoma are two main classes of skin cancer with high and increasing incidence in the world. Surgery freezing (cryotherapy), anti-cancer creams, radiotherapy and a form of light treatment called photodynamic therapy (PDT) are therapeutic choices for skin cancer (Taleghani et al., 2021).

In ICR mouse skin, auraptene suppressed the skin tumorgenesis through inhibition of 12-O-tetradecanoylphorbol-13-acetate (TPA) and suppression of superoxide $\left(\mathrm{O}_{2}^{-}\right)$and intracellular hydroperoxide production in leukocytes (Murakami et al., 1997). In another study, auraptene and 1,4-phenylenebis (methylene) selenocyanate (p-XSC) suppressed the metastasis of melanoma cells to lung in mice. The underlying mechanism was induction of apoptosis and inhibition of metastasis of B16BL6 melanoma cells to lung (Tanaka et al., 2000). 
In human squamous cell carcinoma (SCC) xenografts, auraptene increased the protective effect of all-trans retinoic acid (ATRA) against human skin cancer cell growth in female SCID/bg mice and suppressed the LPS-induced NF- $\kappa$ B activation (Kleiner-Hancock et al., 2010). Barthomeuf et al. reported that auraptene inhibits the growth of human M4Beu melanoma cells ( $\left.\mathrm{IC}_{50} 17.1 \mu \mathrm{M}\right)$ via induction of caspase-dependent apoptosis and cell-cycle arrest in G1 (Barthomeuf et al., 2008).

\section{Ovarian Cancer}

Cervical and ovarian cancers are among the most common gynecologic cancers. Surgery, chemotherapy, and radiation are among the treatment plans (Koh et al., 2015). Like other cancers, herbs and phytocompounds are being progressively introduced as efficient complementary treatments for gynecologic cancers.

Between umbelliprenin and auraptene, auraptene showed more cytotoxic effects against Hela cancer cells via downregulation of $\mathrm{MCl}-1$ gene expression (Motlagh and Gholami, 2017). Auraptene has been reported to decrease the viability of human cervical and ovarian cancer cells and suppresses the migration and invasion of Hela and A2780 cell line by reduction of matrix metalloproteinase-2 (MMP-2) and metalloproteinase-9 (MMP-9) enzymatic activity, respectively (Jamialahmadi et al., 2018). Maleki et al. reported that prenylation at position six of the coumarin ring significantly improved the anticancer activity of aurapten. In this study, eight coumarins were examined and among them umbelliprenin, auraptene, umbelliferone and herniarin with prenylation substitution at position six indicated the best anticancer activity, especially against cervical cancer, with minimal cytotoxicity on normal cells (Maleki et al., 2020).

\section{Esophageal Cancer}

Esophageal cancer is the seventh common cancer in humans. In a study conducted by Saboor-Maleki et al., auraptene upregulated P53 and P21 and downregulated the expression of stem-like cancer cell markers such as CD44 (cluster of differentiation 44), BMI-1 (B cellspecific moloney murine leukemia virus integration site 1 ) and increased the sensitivity of esophageal squamous cell carcinoma (ESCC) to paclitaxel, cisplatin, and 5-fluorouracil (Saboor-Maleki et al., 2017). In another study on esophageal carcinoma cell line (KYSE-30), auraptene down-regulated the $\mathrm{MCl}-1$ gene expression and indicated more cytotoxic effect in comparison with umbelliprenin (Motlagh and Gholami, 2017).

\section{Other Cancer}

Jun et al., showed that auraptene, from leaves of Z. schinifolium, on Jurkat $\mathrm{T}$ cells induce apoptosis through activation of caspase cascade (caspase-8 and caspase-3), degradation of PARP and suppression of Bcl-xL (Jun et al., 2007). In comparison between cytotoxic effects of auraptene and umbelliprenin on Jurkat cells, auraptene was more cytotoxic than umbelliprenin and down-regulated Mcl-1 mRNA expression (Motlagh and Gholami, 2017).

In male F344 rats, dietary administration of auraptene suppressed the carcinogenic activity of 4-nitroquinoline 1oxide (4-NQO) and inhibited development of oral neoplasms, increased the activity of gluthathione S-transferase (GST) and quinone reductase (QR) in the tongue and liver and decreased dysplastic lesions (Tanaka et al., 1998b).

\section{PHARMACOKINETICS OF AURAPTENE}

The pharmacokinetics of auraptene has been evaluated in several studies. Ye et al. determined the pharmacokinetics of auraptene in rat plasma using LC-MS/MS method. Data showed that a dose range of $0.5-200 \mathrm{ng} / \mathrm{ml}$ of auraptene was safe and bioavailability of oral administration of auraptene was merely $8.5 \%$ in rats (Ye et al., 2016). In another study, the absorption and metabolism of auraptene in rodent models was examined. The result indicated that oral administration of AUR at $50-200 \mathrm{mg} / \mathrm{kg}$ body wt induced glutathione S-transferase (GST) activity and xenobiotic phase II enzymes, and indicated chemopreventive effects in rodents. These effects increase, absorption and stable (stabilize) localization in the colon and liver (Murakami et al., 2000). Auraptene showed higher absorption rate in comparison with 7-ethoxycoumarin, with longer life span due to the presence of the geranyloxyl side chain (Kuki et al., 2008).

\section{TOXICOLOGY}

The acute toxicity of orally administrated auraptene in rats was investigated and different concentrations of the compound (125-2,000 mg/kg body weight) had no effect on mortality. However, administration of auraptene demonstrated some differences in ALP, ALT, AST, blood urea, total bilirubin, total protein, haematocrit, hemoglobin, RBC count, platelet count and $\mathrm{MCHC}$ (mean corpuscular haemoglobin concentration) in AURtreated animals as compared to the controls but all were in normal reference ranges. Histopathological examination of organs such as liver, kidneys, bone marrow, heart and lungs indicated no toxic effects of auraptene and showed the safety of the compound (Vakili et al., 2017).

\section{CONCLUSION}

This review evaluated the effects of auraptene on different cancer cells both in vivo and in vitro. Auraptene had inhibitory and chemo-preventive effects on the proliferation, tumorigenesis and growth of several cancer cell lines through increase in the activity of glutathione S-transferase, formation of DNA adducts and reduction of the number of aberrant crypt foci. Auraptene exhibits anticancer effects via targeting different cell signaling pathways such as cytokines, genes modulating cellular proliferation, growth factors, transcription factors and apoptosis.

Modulation of Bcl-2, increase in amount of Bax protein, reduction of MMP-2 and MMP-9, inhibition of NF- $\mathrm{B}$, activation of caspase and p53-independent, suppression of superoxide $\left(\mathrm{O}_{2}^{-}\right)$, downregulation of $\mathrm{Mcl}-1$ mRNA expression and reduction of mitochondrial membrane potential are important mechanisms for the cytotoxic and anticancer effects of auraptene. Low cytotoxic $\mathrm{IC}_{50} \mathrm{~s}$ 
values of auraptene demonstrated its potency as a worthy phytochemical for cancer treatment. However, lack of clinical evaluation has made it difficult to use auraptene in conventional chemotherapeutic regimens for cancer treatment.

In conclusion, auraptene has an excellent safety profile and the ability to affect multiple molecular targets which are important in the prevention and/or management of a number of cancers. However, further studies and more clinical trials are needed to fully elucidate the putative potential of auraptene as an effective anticancer agent.

\section{AUTHOR CONTRIBUTIONS}

SE: Data curation, search for data, Writing-original draft, made the graphical figures, prepare the draft. ZT-N: Conceptualization,

\section{REFERENCES}

Barthomeuf, C., Lim, S., Iranshahi, M., and Chollet, P. (2008). Umbelliprenin from Ferula Szowitsiana Inhibits the Growth of Human M4Beu Metastatic Pigmented Malignant Melanoma Cells through Cell-Cycle Arrest in G1 and Induction of Caspase-dependent Apoptosis. Phytomedicine 15 (1-2), 103-111. doi:10.1016/j.phymed.2007.04.001

Bibak, B., Shakeri, F., Barreto, G. E., Keshavarzi, Z., Sathyapalan, T., and Sahebkar, A. (2019). A Review of the Pharmacological and Therapeutic Effects of Auraptene. BioFactors 45 (6), 867-879. doi:10.1002/biof.1550

Charmforoshan, E., Karimi, E., Oskoueian, E., Es-Haghi, A., and Iranshahi, M. (2019). Inhibition of Human Breast Cancer Cells (MCF-7 Cell Line) Growth via Cell Proliferation, Migration, and Angiogenesis by Auraptene of Ferula Szowitsiana Root Extract. Food Measure 13 (4), 2644-2653. doi:10.1007/ s11694-019-00185-6

De Medina, P., Genovese, S., Paillasse, M. R., Mazaheri, M., Caze-Subra, S., Bystricky, K., et al. (2010). Auraptene Is an Inhibitor of Cholesterol Esterification and a Modulator of Estrogen Receptors. Mol. Pharmacol. 78 (5), 827-836. doi:10.1124/mol.110.065250

Derosa, G., Maffioli, P., and Sahebkar, A. (2016). Auraptene and its Role in Chronic Diseases. Nat. Rev. Drug Discov. 929, 399-407. doi:10.1007/9783-319-41342-6_19

Eghbaliferiz, S., Farhadi, F., Barreto, G. E., Majeed, M., and Sahebkar, A. (2020). Effects of Curcumin on Neurological Diseases: Focus on Astrocytes. Pharmacol. Rep. 72, 769-782. doi:10.1007/s43440-020-00112-3

EghbaliFeriz, S., Taleghani, A., and Tayarani-Najaran, Z. (2018). Scutellaria: Debates on the Anticancer Property. Biomed. Pharmacother. 105, 1299-1310. doi:10.1016/j.biopha.2018.06.107

Epifano, F., Genovese, S., Miller, R., and Majumdar, A. P. N. (2013). Auraptene and its Effects on the Re-emergence of Colon Cancer Stem Cells. Phytother. Res. 27 (5), 784-786. doi:10.1002/ptr.4773

Fu, L., Han, B., Zhou, Y., Ren, J., Cao, W., Patel, G., et al. (2020). The Anticancer Properties of Tanshinones and the Pharmacological Effects of Their Active Ingredients. Front. Pharmacol. 11, 193. doi:10.3389/fphar.2020.00193

Gao, X., Wang, C., Ning, C., Liu, K., Wang, X., Liu, Z., et al. (2018). Hepatoprotection of Auraptene from Peels of Citrus Fruits against Thioacetamide-Induced Hepatic Fibrosis in Mice by Activating Farnesoid X Receptor. Food Funct. 9 (5), 2684-2694. doi:10.1039/c8fo00107c

Hara, A., Sakata, K., Yamada, Y., Kuno, T., Kitaori, N., Oyama, T., et al. (2005). Suppression of Beta-Catenin Mutation by Dietary Exposure of Auraptene, a Citrus Antioxidant, in N,N-diethylnitrosamine-induced Hepatocellular Carcinomas in Rats. Oncol. Rep. 14 (2), 345-351. doi:10.3892/or.14.2.345

Hayashi, K., Suzuki, R., Miyamoto, S., Shin-ichiroh, Y., Kohno, H., Sugie, S., et al. (2007). Citrus Auraptene Suppresses Azoxymethane-Induced Colonic Preneoplastic Lesions in C57BL/KsJ-db/dbMice. Nutr. Cancer 58 (1), 75-84. doi:10.1080/01635580701308216
Data curation, search for data, Writing-review and editing, spelling editing. NT-N: Writing-review and editing and spelling editing.

\section{FUNDING}

This work was supported by Research affair of Birjand and Mashhad University of medical Sciences.

\section{ACKNOWLEDGMENTS}

The authors wish to thanks Birjand and Mashhad University of Medical Sciences.

Jalilzadeh, N., Samadi, N., Salehi, R., Dehghan, G., Iranshahi, M., Dadpour, M. R., et al. (2020). Novel Nano-Vehicle for Delivery and Efficiency of Anticancer Auraptene against colon Cancer Cells. Sci. Rep. 10 (1), 1-19. doi:10.1038/ s41598-020-58527-0

Jamialahmadi, K., Salari, S., Alamolhodaei, N. S., Avan, A., Gholami, L., and Karimi, G. (2018). Auraptene Inhibits Migration and Invasion of Cervical and Ovarian Cancer Cells by Repression of Matrix Metalloproteinasas 2 and 9 Activity. J. Pharmacopuncture. 21 (3), 177-184. doi:10.3831/KPI.2018.21.021

Jang, Y., Han, J., Kim, S. J., Kim, J., Lee, M. J., Jeong, S., et al. (2015). Suppression of Mitochondrial Respiration with Auraptene Inhibits the Progression of Renal Cell Carcinoma: Involvement of HIF-1a Degradation. Oncotarget 6 (35), 38127-38138. doi:10.18632/oncotarget.5511

Jun, D. Y., Kim, J. S., Park, H. S., Han, C. R., Fang, Z., Woo, M. H., et al. (2007) Apoptogenic Activity of Auraptene of Zanthoxylum Schinifolium toward Human Acute Leukemia Jurkat T Cells Is Associated with ER Stress-Mediated Caspase-8 Activation that Stimulates Mitochondria-dependent or -independent Caspase cascade. Carcinogenesis 28 (6), 1303-1313. doi:10.1093/carcin/bgm028

Kaur, J., and Kaur, G. (2015). An Insight into the Role of Citrus Bioactives in Modulation of colon Cancer. J. Funct. Foods 13, 239-261. doi:10.1016/ j.jff.2014.12.043

Kawabata, K., Murakami, A., and Ohigashi, H. (2006a). Auraptene Decreases the Activity of Matrix Metalloproteinases in Dextran Sulfate Sodium-Induced Ulcerative Colitis in ICR Mice. Biosci. Biotechnol. Biochem. 70, 3065. doi:10.1271/bbb.60393

Kawabata, K., Murakami, A., and Ohigashi, H. (2006b). Citrus Auraptene Targets Translation of MMP-7 (Matrilysin) via ERK1/2-dependent and mTORindependent Mechanism. FEBS Lett. 580 (22), 5288-5294. doi:10.1016/ j.febslet.2006.08.072

Kitano, M., Wanibuchi, H., Kikuzaki, H., Nakatani, N., Imaoka, S., Funae, Y., et al. (2000). Chemopreventive Effects of Coumaperine from Pepper on the Initiation Stage of Chemical Hepatocarcinogenesis in the Rat. Jpn. J. Cancer Res. 91 (7), 674-680. doi:10.1111/j.1349-7006.2000.tb00998.x

Kleiner-Hancock, H. E., Shi, R., Remeika, A., Robbins, D., Prince, M., Gill, J. N., et al. (2010). Effects of ATRA Combined with Citrus and Ginger-Derived Compounds in Human SCC Xenografts. BMC Cancer 10 (1), 394. doi:10.1186/ 1471-2407-10-394

Koh, W.-J., Greer, B. E., Abu-Rustum, N. R., Apte, S. M., Campos, S. M., Cho, K. R., et al. (2015). Cervical Cancer, Version 2.2015. J. Natl. Compr. Canc Netw. 13 (4), 395-404. doi:10.6004/jnccn.2015.0055

Kohno, H., Suzuki, R., Curini, M., Epifano, F., Maltese, F., Gonzales, S. P., et al. (2006). Dietary Administration with Prenyloxycoumarins, Auraptene and Collinin, Inhibits Colitis-Related colon Carcinogenesis in Mice. Int. J. Cancer 118 (12), 2936-2942. doi:10.1002/ijc.21719

Krishnan, P., and Kleiner-Hancock, H. (2012). Effects of Auraptene on IGF1 Stimulated Cell Cycle Progression in the Human Breast Cancer Cell Line, MCF-7. Int. J. Breast Cancer. 2012, 502092. doi:10.1155/2012/ 502092 
Krishnan, P., Yan, K. J., Windler, D., Tubbs, J., Grand, R., Li, B. D., et al. (2009). Citrus Auraptene Suppresses Cyclin D1 and Significantly Delays N-Methyl Nitrosourea Induced Mammary Carcinogenesis in Female Sprague-Dawley Rats. BMC Cancer 9 (1), 259. doi:10.1186/1471-2407-9-259

Kuki, W., Hosotani, K., Ohigashi, H., and Murakami, A. (2008). Metabolism and Absorption of Auraptene (7-geranyloxylcoumarin) in Male SD Rats: Comparison with 7-ethoxycoumarin. Nutr. Cancer 60 (3), 368-372. doi:10.1080/01635580701745327

Lee, J. C., Shin, E. A., Kim, B., Kim, B.-I., Chitsazian-Yazdi, M., Iranshahi, M., et al. (2017). Auraptene Induces Apoptosis via Myeloid Cell Leukemia 1-Mediated Activation of Caspases in PC3 and DU145 Prostate Cancer Cells. Phytother. Res. 31 (6), 891-898. doi:10.1002/ptr.5810

Li, G., Wang, J., Li, X., Xu, J., Zhang, Z., and Si, J. (2018). A New Terpene Coumarin Microbial Transformed by Mucor Polymorphosporus Induces Apoptosis of Human Gastric Cancer Cell Line MGC-803. Arch. Pharm. Res. 41 (6), 646-654. doi:10.1007/s12272-018-1028-0

Maleki, E. H., Bahrami, A. R., Sadeghian, H., and Matin, M. M. (2020). Discovering the Structure-Activity Relationships of Different O-Prenylated Coumarin Derivatives as Effective Anticancer Agents in Human Cervical Cancer Cells. Toxicol. Vitro. 63, 104745. doi:10.1016/j.tiv.2019.104745

Moon, J. Y., Kim, H., and Cho, S. K. (2015). Auraptene, a Major Compound of Supercritical Fluid Extract of Phalsak (Citrus Hassaku Hort Ex Tanaka), Induces Apoptosis through the Suppression of mTOR Pathways in Human Gastric Cancer SNU-1 Cells. Evid. Based. Complement. Alternat. Med. 2015, 402385. doi:10.1155/2015/402385

Motlagh, F. M., and Gholami, O. (2017). Comparison of Umbelliprenin and Auraptene in Cytotoxic Effects and Myeloid Cell Leukemia Type-1 (Mcl-1) Gene Expression. Indian J. Pharm. Sci. 78 (6), 827-833. doi:10.4172/ pharmaceutical-sciences.1000189

Moussavi, M., Haddad, F., Matin, M. M., Iranshahi, M., and Rassouli, F. B. (2018). Efficacy of Hyperthermia in Human colon Adenocarcinoma Cells Is Improved by Auraptene. Biochem. Cel Biol. 96 (1), 32-37. doi:10.1139/ bcb-2017-0146

Moussavi, M., Haddad, F., Rassouli, F. B., Iranshahi, M., and Soleymanifard, S. (2017). Synergy between Auraptene, Ionizing Radiation, and Anticancer Drugs in colon Adenocarcinoma Cells. Phytother. Res. 31 (9), 1369-1375. doi:10.1002/ ptr.5863

Murakami, A., Kuki, W., Takahashi, Y., Yonei, H., Nakamura, Y., Ohto, Y., et al. (1997). Auraptene, a Citrus Coumarin, Inhibits 12-0-Tetradecanoylphorbol13-Acetate-Induced Tumor Promotion in ICR Mouse Skin, Possibly through Suppression of Superoxide Generation in Leukocytes. Jpn. J. Cancer Res. 88 (5), 443-452. doi:10.1111/j.1349-7006.1997.tb00402.x

Murakami, A., Wada, K., Ueda, N., Sasaki, K., Haga, M., Kuki, W., et al. (2000). In Vitro absorption and Metabolism of a Citrus Chemopreventive Agent, Auraptene, and its Modifying Effects on Xenobiotic Enzyme Activities in Mouse Livers. Nutr. Cancer 36 (2), 191-199. doi:10.1207/s15327914nc3602_8

Ohnishi, H., Asamoto, M., Tujimura, K., Hokaiwado, N., Takahashi, S., Ogawa, K., et al. (2004). Inhibition of Cell Proliferation by Nobiletin, a Dietary Phytochemical, Associated with Apoptosis and Characteristic Gene Expression, but Lack of Effect on Early Rat Hepatocarcinogenesis In Vivo. Cancer Sci. 95 (12), 936-942. doi:10.1111/j.1349-7006.2004.tb03180.x

Saboor-Maleki, S., Rassouli, F. B., Matin, M. M., and Iranshahi, M. (2017). Auraptene Attenuates Malignant Properties of Esophageal Stem-like Cancer Cells. Technol. Cancer Res. Treat. 16 (4), 519-527. doi:10.1177/1533034616650119

Sakata, K., Hara, A., Hirose, Y., Yamada, Y., Kuno, T., Katayama, M., et al. (2004). Dietary Supplementation of the Citrus Antioxidant Auraptene Inhibits N,NDiethylnitrosamine-Induced Rat Hepatocarcinogenesis. Oncology 66 (3), 244-252. doi:10.1159/000078001

Salari, H., Afkhami-Poostchi, A., Soleymanifard, S., Nakhaei-Rad, S., Merajifar, E., Iranshahi, M., et al. (2020). Coadministration of Auraptene and Radiotherapy; a Novel Modality against colon Carcinoma Cells In Vitro and In Vivo. Int. J. Radiat. Biol. 96, 1051-1059. doi:10.1080/09553002.2020.1770359

Sekiguchi, H., Irie, K., and Murakami, A. (2010). Suppression of CD74 Expression and Helicobacter pylori Adhesion by Auraptene Targeting Serum StarvationActivated ERK1/2 in NCI-N87 Gastric Carcinoma Cells. Biosci. Biotechnol. Biochem. 74, 1018-1024. doi:10.1271/bbb.90910
Sekiguchi, H., Takabayashi, F., Irie, K., and Murakami, A. (2012). Auraptene Attenuates Gastritis via Reduction ofHelicobacter pyloriColonization and Proinflammatory Mediator Production in C57BL/6 Mice. J. Med. Food 15 (7), 658-663. doi:10.1089/jmf.2011.1844

Taleghani, A., Eghbali, S., Shokouhnam, P., Emami, S. A., Farhadi, F., Asili, J., et al. (2021). Anti-Melanogenic Activities of Different Extracts from Pistacia Atlantica Subsp. Kurdica. Jundishapur J. Nat. Pharm. Prod. 16 (2), 1-13. doi:10.5812/jinnp.69844

Tanaka, T., Kawabata, K., Kakumoto, M., Hara, A., Murakami, A., Kuki, W., et al. (1998a). Citrus Auraptene Exerts Dose-dependent Chemopreventive Activity in Rat Large Bowel Tumorigenesis: the Inhibition Correlates with Suppression of Cell Proliferation and Lipid Peroxidation and with Induction of Phase II Drug-Metabolizing Enzymes. Cancer Res. 58 (12), 2550-2556. doi:10.1186/ 1471-2407-9-259

Tanaka, T., Kohno, H., Murakami, M., Kagami, S., and El-Bayoumy, K. (2000). Suppressing Effects of Dietary Supplementation of the Organoselenium 1,4phenylenebis(methylene)selenocyanate and the Citrus Antioxidant Auraptene on Lung Metastasis of Melanoma Cells in Mice. Cancer Res. 60 (14), 3713-3716 .

Tanaka, T., de Azevedo, M. B. M., Durán, N., Alderete, J. B., Epifano, F., Genovese, S., et al. (2010). Colorectal Cancer Chemoprevention by $2 \beta$-cyclodextrin Inclusion Compounds of Auraptene and $4^{\prime}$-geranyloxyferulic Acid. Int. J. Cancer 126 (4), 830-840. doi:10.1002/ijc.24833

Tanaka, T., Kawabata, K., Kakumoto, M., Makita, H., Hara, A., Mori, H., et al. (1997). Citrus Auraptene Inhibits Chemically Induced Colonic Aberrant Crypt Foci in Male F344 Rats. Carcinogenesis 18 (11), 2155-2161. doi:10.1093/carcin/ 18.11.2155

Tanaka, T., Kawabata, K., Kakumoto, M., Matsunaga, K., Mori, H., Murakami, A., et al. (1998b). Chemoprevention of 4-nitroquinoline 1-Oxide-Induced Oral Carcinogenesis by Citrus Auraptene in Rats. Carcinogenesis 19 (3), 425-431. doi:10.1093/carcin/19.3.425

Tanaka, T., Yasui, Y., Ishigamori-Suzuki, R., and Oyama, T. (2008). Citrus Compounds Inhibit Inflammation- and Obesity-Related Colon Carcinogenesis in Mice. Nutr. Cancer 60 (S1), 70-80. doi:10.1080/ 01635580802381253

Tang, M., Ogawa, K., Asamoto, M., Hokaiwado, N., Seeni, A., Suzuki, S., et al. (2007). Protective Effects of Citrus Nobiletin and Auraptene in Transgenic Rats Developing Adenocarcinoma of the Prostate (TRAP) and Human Prostate Carcinoma Cells. Cancer Sci. 98 (4), 471-477. doi:10.1111/j.13497006.2007.00417.x

Torre, L. A., Bray, F., Siegel, R. L., Ferlay, J., Lortet-Tieulent, J., and Jemal, A. (2015). Global Cancer Statistics, 2012. CA: A Cancer J. Clinicians 65 (2), 87-108. doi:10.3322/caac.21262

Vakili, T., Iranshahi, M., Arab, H., Riahi, B., Roshan, N. M., and Karimi, G. (2017). Safety Evaluation of Auraptene in Rats in Acute and Subacute Toxicity Studies. Regul. Toxicol. Pharmacol. 91, 159-164. doi:10.1016/j.yrtph.2017.10.025

Yang, J. D., Hainaut, P., Gores, G. J., Amadou, A., Plymoth, A., and Roberts, L. R. (2019). A Global View of Hepatocellular Carcinoma: Trends, Risk, Prevention and Management. Nat. Rev. Gastroenterol. Hepatol. 16, 589-604. doi:10.1038/ s41575-019-0186-y

Ye, X., Ouyang, H., Zhong, L., Li, T., Rao, X., Feng, Y., et al. (2016). Rapid and Sensitive LC-MS/MS Method for the Determination of Auraptene in Rat Plasma and its Application in a Pharmacokinetic and Bioavailability Study in Rats. Genet. Mol. Res. 15, 1-11. doi:10.4238/gmr.15028786

Conflict of Interest: The authors declare that the research was conducted in the absence of any commercial or financial relationships that could be construed as a potential conflict of interest.

Copyright $\odot 2021$ Tayarani-Najaran, Tayarani-Najaran and Eghbali. This is an open-access article distributed under the terms of the Creative Commons Attribution License (CC BY). The use, distribution or reproduction in other forums is permitted, provided the original author(s) and the copyright owner(s) are credited and that the original publication in this journal is cited, in accordance with accepted academic practice. No use, distribution or reproduction is permitted which does not comply with these terms. 


\section{GLOSSARY}

ACAT: cholesterol acyltransferase

ACF: aberrant crypt foci

ALDH1: aldehyde dehydrogenase 1

AOM: azoxymethane

ATRA: all-trans retinoic acid

AUR: auraptene

BMI-1: B cell-specific moloney murine leukemia virus integration site 1

CD44: cluster of differentiation 44

COX-2: cyclooxygenase-2

ERs: estrogen receptors

ERK1/2: extracellular signal-regulated kinase

ESCC: esophageal squamous cell carcinoma

GATA6: GATA binding protein 6

GST: gluthathione S-transferase

HIF-1 $\alpha$ : hypoxia-inducible factor $1 \alpha$

IGF-1: insulin-like growth factor-1

iNOS: inducible nitric oxide synthase
MMP9: matrix metallopeptidase 9

MMP2: matrix metallopeptidase 2

Mcl-1: myeloid cell leukaemia Type-1

NF-кB: nuclear factor-kappaB, Stat3

NF-E2: nuclear factor erythroid 2

4-NQO: 4-nitroquinoline 1-oxide

PARP: poly (ADP-ribose) polymerase

PCNA: proliferating cell nuclear antigen

PDT: photodynamic therapy

QR: quinone reductaseand

RCC: renal cell carcinoma

SCC: squamous cell carcinomas

TNF- $\boldsymbol{\alpha}$ : tumor necrosis factor-a, signal transducer and activator of transcription 3

TPA: tetradecanoylphorbol-13-acetate

TUNEL: transferase dUTP nick end labeling

VEGFR-1: Vascular endothelial groth factor 